RESEARCH ETHICS

\title{
Research ethics committees and paternalism
}

\author{
S J L Edwards, S Kirchin, R Huxtable
}

J Med Ethics 2004;30:88-91. doi: 10.1136/jme.2002.000166

In this paper the authors argue that research ethics committees (RECs) should not be paternalistic by rejecting research that poses risk to people competent to decide for themselves. However it is important they help to ensure valid consent is sought from potential recruits and protect vulnerable people who cannot look after their own best interests. The authors first describe the tragic deaths of Jesse Gelsinger and Ellen Roche. They then discuss the following claims to support their case: (1) competent individuals are epistemologically and ethically in the best position to say which risks are reasonable for them, so RECs should be no more restrictive than the "normal" constraints on people taking risks with themselves; (2) RECs do not judge individual competence (that is for researchers and psychiatrists); (3) individual liberty is mostly limited by what serves the public interest, and RECs do not determine public interest; (4) RECs may have a paternalistic role in preventing exploitation of competent people vulnerable to the use of incentives, and in protecting the interests of incompetent people; however, (5) the moral and political authority of RECs has not been established in this respect.

See end of article for authors' affiliations

Correspondence to S J L Edwards, Centre for Ethics in Medicine, University of Bristol 73 St Michael's Hill, Bristol BS2 8BH, UK' sarah.edwards@ bristol.ac.uk

Received 10 April 2002 Revised 9 May 2003 Accepted 2 June 2003
$\mathrm{T}$ he role and remit of research ethics committees (RECs) is still under review, despite much debate since it was first suggested, in the 1975 amendments to the Helsinki Declaration, that ethics committees should be created to review research in medicine. ${ }^{1}$ It is now accepted, in the most recent version of the Declaration (2000), that RECs should protect the rights and interests of research participants by making sure information sheets are adequate and the risk benefit calculus is favourable. ${ }^{2}$ The degree of risk that is deemed acceptable for incompetent patients has been discussed at length and this risk is usually regarded as no more than "minimal", or no more than that which the patient would in any case be exposed to on an everyday basis. ${ }^{3}$ Research may also be designed to benefit the participant and may therefore justify exposing him to higher than "minimal risk". While there are problems with defining "minimal risk", there is not the same level of discussion or agreement concerning the level of risk it is acceptable to expose competent people to with their consent, especially in relation to therapeutic research where the expected benefits might outweigh the risks. Since their conception, RECs in various different countries have assumed the specific role of protecting research participants from harm, although this aspect of their function is open to ambiguous interpretation. Current guidance for ethics committees in the UK states that "there are some situations, such as the treatment of serious disease, where it is ethical for research studies to involve more than minimal risk". ${ }^{4}$ Besides this lack of clarity, there is growing reluctance, especially among representatives of patients with HIV or AIDS, to acknowledge this form of "protectionism" or paternalism as a legitimate role for RECs. ${ }^{5}$ We define strong paternalism in the conventional way to mean overriding a person's autonomy for his or her own good. ${ }^{6}$ Our principal aim is to concentrate on UK RECs, but it is worth noting that our position is theoretically applicable to RECs in other countries. ${ }^{7}$

In this paper we stress that RECs have a very important role to play in helping to ensure that valid consent is sought from potential recruits. They could even insist on further safeguards than are routinely required to ensure that consent is valid. However, we argue that RECs should not generally be protective or paternalistic by rejecting research that poses risk to people who are competent to decide for themselves. They do, of course, have a part to play in protecting vulnerable people who cannot look after their own best interests. We will first describe the tragic deaths of Jesse Gelsinger (who participated in a gene therapy trial) and, more recently, Ellen Roche (who participated in a baseline physiological test which induced asthma like reactions in healthy people). We will then discuss the following: (1) individual recruits are in the best position to say what risks are reasonable for them, so RECs should not be more restrictive than the "normal" constraints on people taking risks with themselves; (2) RECs do not judge individual competence (that is something for researchers and psychiatrists); (3) individual liberty is limited, at least in large part, by what serves the public interest, but RECs play little role in determining the public interest; (4) RECs may have a paternalistic role to play in preventing exploitation of competent though vulnerable people through incentives; however, (5) the moral and political authority of RECs has not been established in this respect.

\section{THE CASES OF JESSE GELSINGER AND ELLEN ROCHE}

The $B M J$ reported the deaths of Jesse Gelsinger in March 2000 and Ellen Roche in June 2001, ${ }^{89}$ both of whom agreed to expose themselves to the

Abbreviations: REC, research ethics committee 
risks associated with taking part in research for purely altruistic reasons. Gelsinger's altruism consisted in firstly rejecting standard treatment of diet and drug therapy for an inherited metabolic disorder, and secondly, exposing himself to the risks associated with a high dose of gene therapy in a phase 1 trial for no realistic or expected benefit. Roche, who was a healthy volunteer, agreed to take hexamethonium and inhale methacholine to constrict her lungs to see if, by breathing deeply, she could overcome its effects without the need of a bronchodilator or common asthma treatment. Both Gelsinger and Roche were competent to give valid consent. The legal controversies hinged mainly on whether they had been given material information on earlier adverse effects of the new treatments and hence had genuinely understood their respective positions. ${ }^{10}$ Imagine, for the sake of argument, that the two cases were more straightforward and that they had understood all the relevant information such that their consent had been valid. Even with valid consent, it is not obvious that they should have participated. Savulescu argues, in line with current guidelines, that ethics review of research is not only about consent, but also about an objective evaluation of what expected harm is reasonable for participants to take. ${ }^{11}$ More strongly, he insists that "The first responsibility of ethics committees is to ensure that the expected harm associated with participation is reasonable $\mathrm{e}^{\prime \prime}{ }^{10}$ When it comes to competent individuals we disagree. Research ethics committees should concern themselves only with helping to ensure consent is genuine, and not with trying to stipulate what level of risk is reasonable or unreasonable.

\section{WHO ASSESSES WHICH RISKS ARE REASONABLE?}

Judgments that involve balancing the value of research against the risks associated with it should be made primarily by the potential recruits themselves. A competent person would have to take into account all factors relevant to him or her. Some people may have dependants and being altruistic towards future patients may not be compatible with concern for one's relatives. There will still be cases where individuals do not have anything to lose by being altruistic, for example if they have a terminal illness, or where there is unlikely to be any emotional consequences in the event of injury.

We must accept that there should generally be some paternalistic limits on competent people's liberty, although there is no reason why RECs should be more restrictive than the "normal" constraints on people taking risks with themselves. These "normal" constraints are usually legal. At one obvious extreme, the law draws relatively clear, if sometimes arguably arbitrary, lines around the circumstances in which a patient can consent to his own death. While suicide is permissible, assisted suicide and active voluntary euthanasia are prohibited. The debate surrounding the latter concerns conflicting considerations such as respect for autonomy and the sanctity of human life, a debate which has been refuelled by the Human Rights Act 1998, with its prohibition on intentional killing and yet insistence that privacy must be respected. ${ }^{12}$

In the present context, however, a more apposite prohibition is the law's refusal to allow a competent living person to donate a vital organ-for example, a heart - to save the life of another, even if both are members of a close family. ${ }^{13}$ Even where the death of the person is not in issue, however, the law has shown a willingness to curtail the activities of freely consenting, competent, and healthy persons. ${ }^{14-16}$

\section{COMPETENCE AND JUDGMENT OF RISK}

A research ethics committee cannot itself assess individual competence on a purely pragmatic basis because it does not come into contact with patients. It does not have the necessary insight into individuals' beliefs, values, and reasoning abilities. Assessment of competence is usually left to the researcher who does have direct and personal contact with potential recruits. (To point out, both patients and healthy volunteers alike are assessed before being treated either in a routine or a research setting.) Briefly, the test of competence for a young person between the ages of 16 and 18 years, or an adult, is the Re C test. This test has three stages: (1) could the patient comprehend and retain the necessary information; (2) was he able to believe it, and (3) was he able to weigh the information, balancing risks and needs, so as to arrive at a choice? There are legal checks and balances on researchers, of course, to make sure they exercise reasonable judgment in assessing competence. If the outcome were contested, then the medical researcher may have to defend himself in a court of law. If, for example, the claim were to be in negligence, the court would consider whether the researcher conducted himself in line with the appropriate standard of care. At base, this means that the researcher must act "reasonably", including in assessing competence. In relation to medicine, this requirement remains tethered to the Bolam standard, whereby judgment of a "responsible body of medical opinion" could be sought. An REC may thus not even be in a position to say more generally that anyone (any reasonable person not a particular person) who accepts certain risks must ipso facto be incompetent. Rather, the Bolam standard and its recent extensions may be more relevant alongside guidelines on assessing competence and treating the incompetent. ${ }^{17}$

However, most researchers have the well recognised potential conflict of interests between benefiting society as a whole by doing research and benefiting the individual participant. And some researchers outside medicine do not even owe a duty of care to the participants of their research. Societal interests could easily override the rights and welfare of participants and this is why independent review is so important. While recognising that adults over the age of 18 years are presumed to be competent, the researcher should routinely have access to any psychiatric testing. RECs could insist that the presumption of competence be changed so that all participants are assessed in detail before they are allowed to participate in research that is perceived by the REC to be particularly dangerous. ${ }^{18}$

It should be noted that imposing any further safeguards on the very assessment of individual competence is not itself paternalism in any strong sense. Our main argument is that, assuming an individual is competent, an REC should not prevent his or her participation in a research project that he or she would have consented to in the proper way. Our above comments are concerned with all types of risk related to answering a given research question. If an REC deems some aspect of the trial to involve unnecessary risks then it can raise this matter with the researcher. The REC could insist on the wording of information sheets such that it is clear that there is a potential disagreement over the necessity of the risk involved, but could not prevent researchers inviting people to participate. It could also always refer matters to the Health Authority.

The current move in research ethics seems to be towards widening access to ensure that more people have a chance to participate, although not necessarily in very risky research. ${ }^{19}$ There was a case in the United States, which, though not litigated, influenced policy making, and involved prisoners who contended that the then Food and Drug Agency regulations were an unconstitutional deprivation of their rights to serve as research subjects. ${ }^{20}$ The prisoners expected good care from the research unit and their motives were not altogether altruistic, but the point that their liberties should be respected is an important one. 


\section{RESEARCH RISK AND THE PUBLIC INTEREST}

The law will rule out both self interested and altruistic consensual conduct where these are deemed contrary to public policy or otherwise "unreasonable". It is commonly assumed that scientific research in medicine is inevitably in the public interest, but, as McNeill points out, it is not always a safe assumption and separates out the interests of the researcher, the scientific community, and society respectively. ${ }^{5}$ For example, the public interest could be threatened by research using competent people who had given valid consent, if these participants were to die frequently or in particularly terrible circumstances. Indeed, at a meeting of the Food and Drug Agency in 2002, the Director of Cellular and Gene Therapies cited the case of Jesse Gelsinger as playing a big part in undermining public confidence in clinical trials. ${ }^{21}$ This would have obviously devastating consequences for society as a whole. Any protective limits here would be for the benefit of society generally, rather than protecting individual welfare specifically. This possible justification for imposing limits on individual liberty could also apply to other areas, such as live organ donation, which also carries risks and sometimes results in the death of a healthy donor without attracting the same level of media coverage as the two research cases above had done. In January 2002, such operations were temporarily stopped following a death during an operation to give part of a donor's liver to his brother at Mount Sinai Hospital in Manhattan, USA. ${ }^{9}$ It is very difficult to judge in advance how many deaths or other adverse outcomes the public would accept for the furtherance of science or any other practice except where "normal" constraints have been set in law as discussed above. In any case, there may be so few competent and informed people in practice who would be willing to undergo very risky experiments (assuming for now that there are no countervailing inducements) that a dangerous study may not be worth starting at all.

\section{RECS, THREATS, AND INCENTIVES}

We now discuss one function of RECs where there is room for paternalism, although we raise a concern about this function in the following section. Sometimes a participant may be offered payment of some kind, or threatened with the withdrawal of privileges, in exchange for participating in research that exposes him to a degree of risk. These types of psychological manipulation could affect a person's decision, especially when facing limited choice. Although sums paid might not be great, financial inducements generally are potentially exploitative and threats potentially coercive and are, for these reasons, unethical. ${ }^{22-24}$

An REC can have two possible functions, then, with respect to such psychological manipulation. Firstly, they should make sure that the researcher has not threatened possible participants in any way. However, this is no challenge to our position as we are discussing potential participants who can give valid consent. The existence of a threat prevents such consent.

A second suggestion is more challenging. If financial inducements are offered and the REC deems that they have been offered so as to exploit those who are vulnerable to financial suggestion, for example the less well off, then arguably it should prevent the trial. However, there are problems. For example, how might an REC decide who the less well off are? How can RECs decide if the money offered is primarily designed to manipulate, and further to exploit, those who cannot resist its lure? And so on. One might think that an REC should not be allowed to prevent a trial in this manner, as one might think they have questionable moral authority. We have already argued that RECs should only protect the value systems of individuals as regards the individual's reasons for entering trials, not impose the REC's own ideas. We are now suggesting that RECs should have some discretion to make value decisions of the sort above. However, because these decisions affect other people's freedom to enter trials (that is, the trial would probably not occur as a result of the REC), then we think that, at the very least, RECs should be monitored heavily in this regard and engage in a proper debate on the issue.

\section{THE MORAL AND POLITICAL AUTHORITY OF RECS}

In this final section we show briefly why there is a significant worry relating to the moral authority of RECs as they stand, in respect of paternalism and the above discussion. To be bold, clearly we have emphasised the importance of the autonomy of potential recruits. One might think that even if this is an important value, other values such as beneficence and non-maleficence are just as, if not more, important and that RECs should be guided by them. ${ }^{25}$ Even if this is so, this present section is controversial because we raise the question of whether it is so certain that RECs have the moral and political authority to make decisions guided by such values. Secondly, we make one suggestion as to how this worry might be alleviated, although this creates further problems.

As they stand, RECs inherit some authority through their association with the medical establishment. However, the current moral authority of health care professionals is itself in flux. Paternalism in medical practice is no longer seen as an acceptable way to treat patients and they continue to lobby for their fundamental freedoms. In most cases, health care policies are governed, in a wider sense, by the people who are elected to state power, but this is insufficient to ensure a just system in biomedical research, one that fully protects the rights and interests of its participants. What is the alternative? RECs are commenting on decisions that affect members of the public; specifically potential participants, but also those who might benefit from research in the long term. Perhaps, then, their moral authority might be grounded in the wishes and interests of the public. This general line has the advantage of removing the seeming paradox between protecting individual freedom (through informed consent) and protecting individual interests (through paternalism). In society at large-in Western democracies at least-individuals' rights and freedoms are protected through state intervention. However, this is not problematic, in theory at least, as a state has this authority only because of the consent of the individual members. Consent can be explicit or implicit. The latter is by far the more frequent type, although implied consent is itself problematic.

Research ethics committees in their present form differ from the state. Whereas most people know about the existence of the state, RECs have a very low profile. We suggest that as a minimum requirement, RECs should be promoted and debated in the public arena such that their profile is raised (such as through the Cancer Research Campaign). This might allow one to assume some notion of implicit, informed consent because people would be aware of RECs and might not explicitly object to them. Arguably much of the state's legitimacy in the UK stems from the fact that many of those in power are either elected by the citizens or are chosen to fulfil their duties by those elected. That is, there is some connection between the citizenry and the state. There seems, then, a good prima facie reason for allowing that some form of democratic choice influence the makeup of an REC. McNeill puts forward such a position and suggests that REC members could actively represent the interests of society, the scientific community, and research participants respectively in equal measure. ${ }^{5}$ However, although this seems to be a good way of ensuring that RECs have moral and political authority 
that is separate from professional regulation, democracy has not been, and is unlikely to be, used as the mechanism for recruiting committee members. Who, for example, would be allowed to vote and stand? Indeed, perhaps full democracy will bring its own problems since it seems desirable that a REC comprises the knowledgeable and wise, not merely the popular.

This discussion is very much to the point since in 2004 the European Directive on Good Clinical Practice in Clinical Trials will be implemented in the UK, giving RECs legal status and authority to process and review research. This authority is far from being absolute and the RECs' authority to make substantive judgment about risk is yet to be tested by judicial review.

\section{CONCLUSION}

We have been arguing against the idea that RECs should be extensively paternalistic, yet RECs have a role to play. They are essential in helping to ensure potential participants can give genuine consent by having all the material information, and by understanding the language in which the information is written. The only paternalistic role that RECs should be allowed is with regard to inducements. However, we have raised some general worries regarding their moral and political authority in these matters and we think that there is still much to debate about the authority that RECs should have.

\section{ACKNOWLEDGEMENTS}

We would like to thank Professor Tony Hope for his detailed and considered comments on this paper.

\section{Authors' affiliations}

S J L Edwards, S Kirchin, R Huxtable, University of Bristol, Bristol, UK

\section{REFERENCES}

1 World Medical Association. Declaration of Helsinki 1964, 1975 Tokyo, Japan.

2 World Medical Association. Declaration of Helsinki 2000, Edinburgh, UK.

3 Royal College of Physicians. Research on Healthy Volunteers: a working party report. London: RCP, 1986. The concept of "minimal risk" should not be confused with minimising unnecessary risks.

4 Section 11.14 Guidelines on the Practice of Ethics Committees in Medical Research involving human subjects. A report of the Royal College of Physicians, London: 1990.
5 McNeill PM. The Ethics and Politics of Human Experimentation. Cambridge: Cambridge University Press, 1993

6 Beauchamp and Childress. Principles of Medical Ethics. Oxford: Oxford University Press, 1994.

7 Examples of systems that have an explicitly broad remit; see the US Federal Policy for the Protection of Human Subjects (Basic DHHS Policy for Protection of Human Research Subjects), Australian National Statement on Ethical Conduct in Research Involving Humans, and the Canadian Tri-Council Policy. But, although these remits are ostensibly broader than those given to UK RECs, different functions may be performed by different committees. So, whether the research is worth conducting could be examined by a committee different from the REC (and composed of medical scientists only). For comparisons across different countries, see McNeill PM. The Ethics and Politics of Human Experimentation. Cambridge: Cambridge University Press, 1993.

8 News Extra. US faces ethical issues after gene therapy death. BMJ 2000;320:602

9 News roundup. Healthy woman dies in research experiment. 2001;322:1565

10 Savulescu J. Harm, ethics committees and the gene therapy death. J Med Ethics 2001;27:148.

11 Savulescu J. Safety of participants of non-therapeutic research must be ensured. BMJ 1998;16:891-2.

12 Articles 2 and 8 respectively. For a recent example of an attempt to enshrine a right to assisted suicide in English law, see the case of Dianne Pretty R (on the application of Pretty) v DPP (2002) 1 FLR 268, and European Court of Human Rights, see Application No 2346/02 Pretty v UK, (2002).

13 See, generally, the Human Organ Transplants Act 1989.

14 See the Abortion Act 1967.

15 See the Prohibition of Female Circumcision Act 1985.

16 See the Tattooing of Minors Act 1969.

17 Law Commission Mental Incapacity (1995) Report no 231

18 The level of competence required to consent or refuse should not arguably be proportional to the level of risk associated with the project since someone could theoretically be found competent to refuse but not to consent or vice versa. For a lively debate on risk related standards of competence, see Gita S Cale. Continuing the debate over risk-related standards of competence. Bioethics 1999; 13:131-48, and Mark R Wicclair. The continuing debate over risk-related standards of competence. Bioethics 1999;13:149-53, and lan Wilks. Asymmetrical competence. Bioethics 1999;13:154-7.

19 Mastroianni A, Kahn J. Swinging on the Pendulum: Shifting Views of Justice in Human Subjects Research. The Hastings Center Report 2001:31:21-32.

20 Fant and the Upjohn Company $v$ the Department of Health and Human Services et al. Civil Action No 80-72778, US District Court, ED Michigan, 1980.

21 Marwick C. Failure to inform public is undermining confidence in clinical trials. News. BMJ 2002;325:356

22 Wilkinson M, Moore A. Inducement in research. Bioethics 1997; 11:373-89.

23 Macklin R. On paying money to research subjects: 'due' and 'undue' inducements. IRB 1981;3:1-6.

24 Grady C. Money for research participation: does in jeopardize informed consent? [Review] Am J Bioeth 2001;1:40-4.

25 See Charles Weijer. The ethical analysis of risk. J Law Med Ethics 2000;28:344-61, and Michael Baram. Making clinical trials safer for human subjects. Am J Law Med 2000;27:253-82.

\section{Body Parts for Sale Conference}

The Centre for Professional Development at Imperial College London, in collaboration with the Health Care Ethics Forum, is presenting a one day Body Parts for Sale Conference. The meeting is chaired by Professor Raanan Gillon and will be taking place on 23 April 2004. It has been designed to cater for a broad spectrum of professionals with interests in the issues raised by the sale of body parts. The event will be accredited by the Royal College of Physicians for six Continuing Medial Education (CME) units.

For further information, please contact: Bang Nong, Centre for Professional Development, Imperial College London, South Kensington Campus, London SW7 2AZ (tel: +44 (0)20 7594 6882; fax: +44 (0)20 7594 6883; e-mail: cpd@imperial.ac.uk; website: http:// www.imperial.ac.uk/cpd/bodyparts.htm). 